
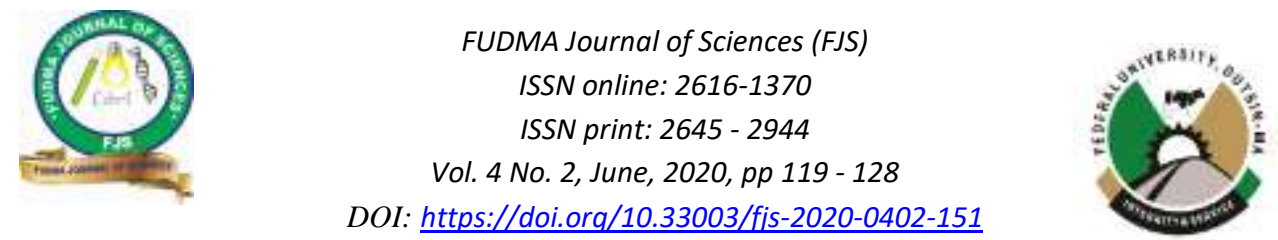

\title{
ANALYSIS OF TOURISM DESTINATION COMPONENTS QF ZARIA URBAN AREA OF KADUNA STATE, NIGERIA
}

\author{
${ }^{* 1}$ Atuk, J. J., ${ }^{2}$ Sarki, L. H., ${ }^{3}$ Bashariya, B. M. \& ${ }^{4}$ Ejeh, B.
}

\author{
${ }^{1}$ Department of Geography and Environmental Management, Ahmadu Bello University Zaria Kaduna State, Nigeria. \\ ${ }^{2}$ Department of Travel and Tourism, National Institute of Hospitality and Tourism, Bagauda Kano State, Nigeria. \\ ${ }^{3}$ Department of geography, Kaduna State University, Nigeria. \\ ${ }^{4}$ Department of Geography and Environmental Management, Ahmadu Bello University Zaria Kaduna State, Nigeria. \\ *Corresponding Author's Email: atukjiyo@gmail.com
}

\begin{abstract}
Tourism is not just a lucrative sector but the fastest growing industry in the world. Many people travel miles to satisfy their pleasure apatite at any destination where satisfaction can be met. But some destinations are flooded while some are scanty. There are many approaches to investigate this and many studies had been done. But despite all these, each destination is unique in terms of its components and attractions combination, this form the basis for this study. The aim of this study is to analyze tourism destination components in Zaria Kaduna State of Nigeria. Tourists' opinions were sampled through questionnaire at various strategic centers to cover all tourism elements at the destination. Data collected were analyzed using Importance Performance Analysis technique (IPA). The results prove attraction to be the primary destination component i.e. main attractant, while accommodation and accessibility as secondary attractants (Facilitators) in the destination. The outcomes suggest major shortcomings that are traced to poor advertisement, insecurity in the destination e.t.c. The study established the state of the attractiveness of Zaria as a tourist destination, what components and elements are attractive and are not and the factors that influence these. In line with these, the study proposes recommendation that the local tourism board needs to be rejuvenated in other to enhance the local tourism industries to improve its attractiveness among others.
\end{abstract}

Keywords: Tourism Destination, Component (attraction accessibility, accommodation), Tourist.

\section{INTRODUCTION}

Over the years tourism had developed with the effort of both public and private investment in the industry. Tourists have also been trooping in continuously to see attractions at various destinations. Zaria as a town in Kaduna State in the savannah part of the country is not left out in having some breath-taking tourist attractions. Attractions and potential are passive elements of the supply system and do not bring benefits to the territory if not correlated with good adapted infrastructures, provision of high accessibility and visibility (Iatu et al, 2011). Therefore tourism destination is a product of its components which are mainly ("3A") attractions, accommodations and accessibility. These components are major factors to determine destination attractiveness for it comprises of all that a tourist wants (attractions) and needs (accommodation and accessibility) and it helps in the development of destinations.
The image of any tourism region is dependent on mosaic of its attractions, accommodation and accessibility (Pearce, 1991). Attraction being the primary component cannot be independent without other two components complimenting. According to Echtner and Ritchie, (2003) in order for tourism to be successfully promoted in the targeted markets, a destination must be favorably differentiated from its competitors, or positively positioned in the minds of the consumers. This indicates that both attractions and customers' perception are important determining factors in any tourism industry. Attractiveness which is the ability of something to be appealing enough to make people visit a place or spend their money is actually derived from the model of gravity force and enables to evaluate territorial impact of inner forces (supply) on outer forces (demand) and vice-versa as there is consistent feed-back. Tourism component as measurement variables in the tourism system seems to better express the relationships between possible and existent tourism resources and between existent

$\star$ In fond memory of a beloved friend and student, Mr. Atuk James Jiyo, who died on $27^{\text {th }}$ June, 2020 in a ghastly motor accident. Until his death, he was a PhD student in the Department of Geography and Environmental Management, Ahmadu Bello University, Zaria. He actively led this work. May his soul rest in perfect peace. Amen. 
and consumed tourism resources (Iatu and Bulai, 2011). Knowing these, it implies that not only potentials that make a supply but both possible and existent tourism components have potential to generate destination attractiveness. Also, the greater the supply of these components the greater will be the demand force (attractiveness) of the tourism industry.

There are numerous attractions in Zaria yet its tourism industry is still at primitive stage of development with no local tourism board. Even at this stage of little or no involvement of public and private sector there is still undeniable tourists' in-flow into Zaria, showing that it is attractive as a tourism destination and this indicate a great benefits to the destination if it will be given proper attention. In Zaria, the local tourism board is absent but the state Ministry of culture and tourism is trying to ensure smooth running of some notable attractions in the state (majorly festivals), also embarking on some public and private partnership to sponsor or develop these attractions. However, it is not performing to expectation due to not having deeper insight into local tourism and this makes its efforts not to have significant influence because little is known about these attractions and their patronage. Although many works had been devoted to the study of tourism in many destinations (Chon, 1990; Chukwuemeka, 2009; Evans et.al, 1989; Kotler et.al. 2005; Moscardo, 2001), also the previous studies in Zaria had done a good work in tourism by identifying and classifying the tourism industry (Muazu, 2010; MSc. Class 08/09, 2009; Oburevu, 2010). Nevertheless there exists a gap about knowing how attractive is Zaria urban area, which of its sectors is the chief enticement, what contributed to its present state? What can be done to boost tourism among many others? So the study of the industry has to go beyond mere identification and classification of its potential attractions for it to attain its best. Hence there is need to investigate deeper by analyzing the tourism components of Zaria as a tourists' destination

\section{MATERIALS AND METHODS}

The research data was in line with the aim of the study and was collected using oral interviews, field survey, structured questionnaire to collect data and because of the primeval nature of tourism in the area, interviews and questionnaires were serve to staff, managements and relevant personnel that are associated to different sectors of the industry. Also data was collected from published and unpublished materials; Journals, textbooks, thesis, dissertations pamphlets, internet and unpublished literatures. Field reconnaissance and personal interviews with experts in the industry, gave the estimation of the tourists in the area to be about 7,500 monthly (averagely). The research used Krejcie and Morgan Sample size table as in James (1997) to determine sample size of the study population. Going by this population size, 365 samples is required. 366 questionnaires were served to tourists at five different centers of which 235 were retrieved (64.21\%): Respondebbbmnts selected were tourists at various centers within the study area. The target population (tourists) was sampled using purposive sampling technique. The distribution of questionnaires was based on the researcher reconnaissance survey of where mainly the tourists can be located within the study area. Also 16 interviews and/or questionnaires was served to staff, managements and relevant personnel that are associated to the 8 identified sectors of the industry. Destination attractiveness was then measured by the estimated number of visited tourists; their evaluation and these were analyzed (through importance and Performance analysis) using relevant set of attributes and elements at the destination). The mean values of importance and performance scores were used as the crossing point in constructing the IPA grid. Achieving the goal of measuring destination attractiveness of a destination requires the understanding of its components and their relationships. There are two ways of examining attractions given by Edward and George (2008):

1) by studying the attractions

2) by exploring the perceptions of those who are attracted by them.

This study established its findings using the second ways as given above. Previous studies done on tourism potentials and attractions of a certain territory focused on studying the attractions such as inventory taking, grouping or summing up indices representing resources, infrastructures or even services (Muazu, 2010, Evans and Chon, 1989; Go and Zhang, 1997, O'Neill et al., 2002) than analyzing their degree of correlation/significance or individual sectoral driving force (pull). This studies fall short of explaining the impact of the static or active tourism territorial elements on regions. Understanding tourists' preferences and their perception of the destination are considered essential inputs to tourism planning and marketing efforts (Kotler et al., 2005). Tourism literature provides only a limited number of studies addressing destination attractiveness. And those studies focused exclusively on the measurement or grouping aspect of attractiveness and ignored the analysis of its components. To evaluate individual sector attractiveness in a tourism destination, an appropriate tool is necessary so as to have a proper evaluation. According to a resource guide for cities (The Cities Alliance, 2007), to assess basic sectoral contributions to an industry, three tools were suggested:

1. Sector share analysis

2. Value-added analysis

3. Economic base analysis

But these tools seem non-applicable to Zaria tourism industry because of the following reasons:

- Sector Share Analysis and Value-Added Analysis address questions like" Which sectors contribute the most to demand, overall employment or output?" and "Which sectors and/or firms are the most important contributors to the local supply?" respectively. But with 
tourism industry that has fluid border, it will be very hard to segregate contribution of a sector from the other because there is great interdependence and interaction between the sectors especially in an area like Zaria where its tourism industry is still experiencing development.

Economic Base Analysis attempts to answer question like "How much of the city's economy is driven by meeting the local population needs (such as recreation, sightseeing) versus selling products and services consumed by tourists?" this is not valid in a study like this because an industry like tourism is targeted at a group of customers which are tourists that come outside the border of supply area and not mainly focusing on the local residents needs.

In addition to these, data base in Zaria tourism industry is very poor and not easy to lay hands on, because there is no body locally coordinating this industry at present.

SWOT analysis can also be an efficient tool in assessing a destination in terms of it performance but IPA technique has capability of exposing a destination better.

Due to these inadequacies in the above named tools, this study applied Importance Performance Analysis (IPA) Technique in analyzing destination attractiveness of Zaria Urban area. The beauty of IPA is that it can help a researcher understand what its customers feel is important to him across a number of relevant variables. In the past, researchers have used IPA framework for service quality research in travel and tourism, and evaluating international tourists' perceived destination attractiveness (Evans and Chon, 1989; Go and Zhang, 1997, O'Neill et al., 2002, Edward and George, 2008). Most of these studies explained service quality assessment for specific tourism products. As an extension of its use, this study attempts to use IPA for evaluating local and international tourists' perceived destination attractiveness for Zaria.

In this study, Important-Performance Analysis (IPA) (as a descriptive tool) will be used both for indicating the need for improvements in some key areas, as well as to reveal the less controllable destination attraction elements on which destination promotion and positioning activities can be based. Moreover, another reason for use of this technique is that most of the attributes used in this study will be assessed at an aggregate level. In view of this, the study will analyze the destination components of Zaria urban area, as perceived by the tourism industry personnel and tourists' visiting Zaria. This will reveal the extent of Zaria as an attraction spot and aid tourism promotion in Zaria urban area in particular and Nigeria as a whole. Importance-Performance Analysis (IPA) technique which emerged from the earlier work of Martilla and James (1977) as cited in Mullins Gary. W et.al, (1987) was used in this study. The IPA technique allows simultaneous comparison of direct performance measure of service quality to the importance rating given by customers for the various quality items being evaluated. The inclusion of customer preference rating in IPA gives a better picture of customers' quality assessment of product or service. According to Barsky (1995) such relative assessments pinpoint clearly, the quality aspects of product or service which contributes greatly to customer satisfaction. As a result, the information derived out of importance-performance analysis (IPA) can aid the development of more focused planning strategies (Ford et al., 1999). This view is confirmed by Lovelock C. et.al (1998) who states that importanceperformance analysis is a useful management tool which can help firms to redirect their scarce resources from low impact areas to high impact areas. This technique is also called Key Driver Analysis. The importance-performance scale is based on the assumption that satisfaction is affected by both the importance of an attribute and perceived performance on the attribute. Designed for ease of transferring results into actions, the scale's end result is a graph indicating appropriate levels of action.

\section{IPA process}

In this method, determinant attributes to be evaluated are presented as two identical lists. These form the basis for two Likert-type scales. On one scale, participants are asked to rate the attributes as to how important these are, while on the other, they rate how well the attraction performs. A mean or median value for each attribute is determined for each scale.

These values are then plotted on a graph (fig 1) with importance as $\mathrm{X}$-axis and performance as $\mathrm{Y}$-axis. The points will fall into one of four quadrants - labeled. For further analysis the ground mean value (GMV) will be established which will be a benchmark for rating the determinant attributes. Aggregates values of attributes are to be calculated, and rate "Good" if its value is higher than the GMV, "Poor" if lower than the GMV and "fair" if its within plus or minus $( \pm) 5 \%$ of the GMV. Kinley T. et.al (2002) likens the four quadrants in IPA to SWOT analysis interpretation.

- $\quad$ Possible Overkill $=$ Strengths $*$ Concentrate Here: Threats

- $\quad$ Keep Up The Good Work = Opportunities * Low Priority $=$ weakness 


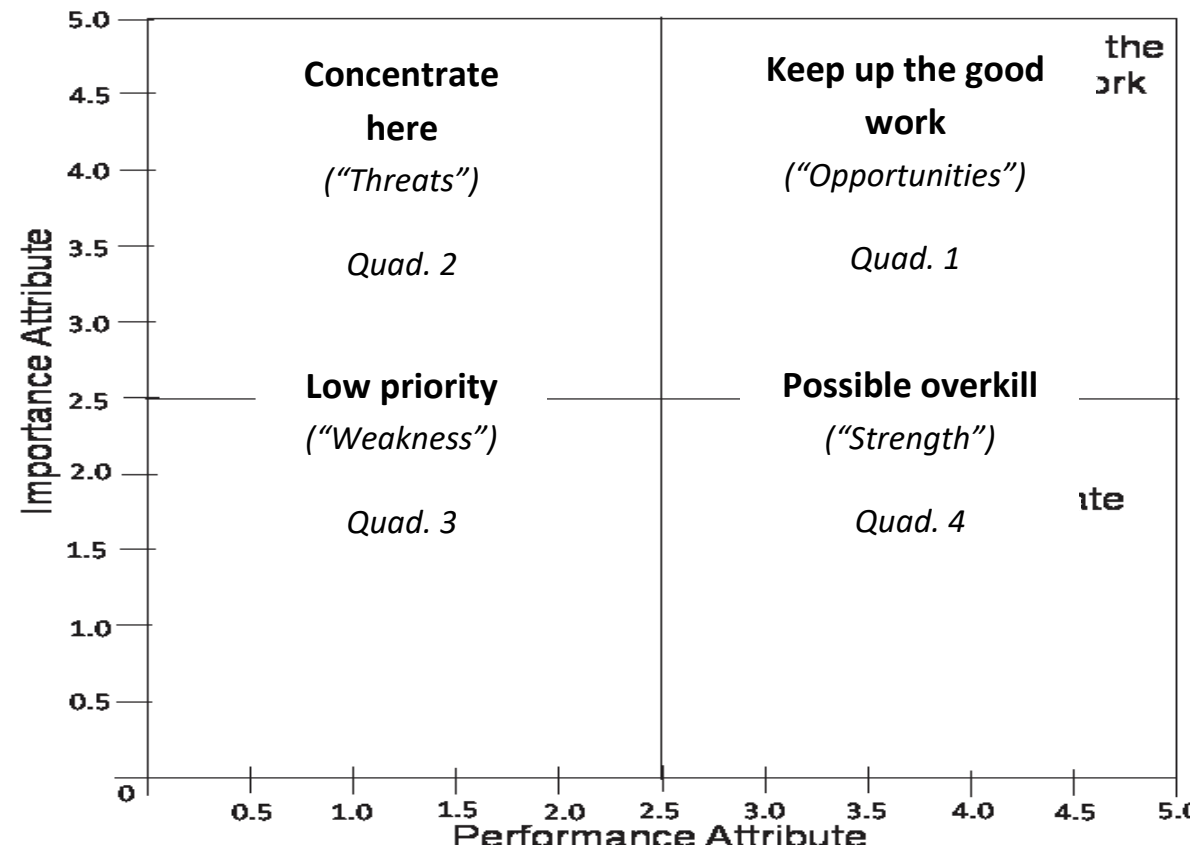

Fig. 1: IPA Grid

Source: Adapted from Edward et.al. 2008

"Keep Up The Good Work," Attributes that are rated high in importance and high in performance / perception score suggest that service providers keep up the 'good' work and increase resources directed towards these areas

"Concentrate Here" Attributes that are rated high in importance and low in performance are areas that the providers should pay particular attention for improvement.

"Low Priority," attributes having low importance rating and a low performance rating suggest that investing resources to these areas may offer only little advantage

"Possible Overkill," attributes rated low in importance and high in performance are areas providers should continue to maintain the level of effort Indicating to administrators/researchers how best to use their resources to upgrade their programs.

By adding other questions, either open- or closed-ended, more information can be gained without adding significantly to the cost. Demographic characteristics, group level characteristics, and information on past experiences will be used to create graphs of different groups for comparison. By asking a few wellstated, open-ended questions, the researchers may learn not only which attributes to concentrate on, but also how they may best be improved. The beauty of IPA is that it can help the industry understand what its customers feel is important to it across a number of relevant variables. In this regard, destination attractiveness will be represented in terms of various tourist attractions and experience elements identified in the qualitative phase of the study, for its inherent appeal to attract tourists to the destination in the first place. The findings of the research will be presented in figures, tables, and percentages,

\section{RESULTS AND DISCUSSION}

As established by previous studies, Zaria is a major tourism destination by virtue of its history, culture and natural endowments. One of the major objectives of the study was to establish the components and elements that help account for this image. To establish the component(s) and attraction elements that are most significant in explaining this image, the IPA technique was employed. The result obtained is shown in Table 1 and Table 2. 
Table 1: Destination attributes mean value

\begin{tabular}{|c|c|c|c|c|}
\hline & Destination Attributes & $\begin{array}{c}\text { Mean } \\
\text { Importance }\end{array}$ & $\begin{array}{c}\text { Mean } \\
\text { Performance }\end{array}$ & Total Mean \\
\hline \multicolumn{5}{|c|}{ PART 1: ATTRACTIONS : } \\
\hline $\mathbf{A}$ & Environment & 3.86 & 3.27 & 3.57 \\
\hline B & Image & 4.16 & 3.54 & 3.85 \\
\hline $\mathbf{C}$ & Fun & 3.60 & 3.53 & 3.75 \\
\hline \multirow[t]{2}{*}{ D } & Style & 3.68 & 3.91 & 3.80 \\
\hline & Attraction aggregate & & & 3.74 \\
\hline \multicolumn{5}{|c|}{ PART 2: ACCOMMODATION: } \\
\hline $\mathbf{E}$ & Staff service quality & 4.27 & 3.89 & 4.08 \\
\hline $\mathbf{F}$ & Room quality & 4.16 & 3.43 & 3.80 \\
\hline $\mathbf{G}$ & Business service & 3.82 & 2.20 & 3.01 \\
\hline $\mathbf{H}$ & Security & 3.80 & 3.28 & 3.54 \\
\hline I & Value and food quality & 3.74 & 2.94 & 3.34 \\
\hline \multirow[t]{3}{*}{$\mathbf{J}$} & General amenities & 3.67 & 3.12 & 3.40 \\
\hline & Accommodation aggregate & & & 3.53 \\
\hline & PART 3: & ACCESSIBILITY: | & & \\
\hline $\mathbf{K}$ & System quality & 3.77 & 3.15 & 3.46 \\
\hline $\mathbf{L}$ & Convenience & 3.40 & 2.92 & 3.16 \\
\hline \multirow[t]{3}{*}{$\mathbf{M}$} & Staff service quality & 3.82 & 3.05 & 3.44 \\
\hline & Accessibility aggregate & & & 3.35 \\
\hline & Grand Mean & 3.82 & 3.25 & 3.54 \\
\hline
\end{tabular}

Source: Field survey, 2018

The findings from Table: 1 established that attractions provide the main explanation for the attractiveness of Zaria as a tourist destination followed by accommodation. Accessibility is the least in importance. The result obtained gave the grand mean value of the attributes as 3.54. The value obtained for the attraction components was 3.74 , a figure that is higher than the grand mean value implying good performance. Accommodation is next with aggregate value of 3.53 (a bit less than the grand mean value) suggesting fair performance. Accessibility with the aggregate value of 3.35 (much lower than the grand mean value) suggested poor performance. Further analysis was carried out on the elements that make-up each component. For the attraction component, four sub-components (image, style, fun and environment) were identified and examined. The value obtained for the image sub-component of 3.85 (higher than the grand mean) indicate to be the most appealing. Style with the value of
3.80 is next in importance. At the value of 3.75 and 3.57, fun and the environment are the least appealing attributes of attraction.

Six attributes were tested under the accommodation component. The study revealed that three attributes out of the six tested had values greater than the grand mean value. The three attribute values are 4.08 for staff service quality, 3.80 for room quality and 3.54 for security. The remaining attributes that fall below the grand mean value were 3.40 for general amenities, 3.34 for value and food quality and 3.01 for business service. All the three attributes tested under accessibility fell below the grand mean value. The attribute values are, 3.46 for system quality, 3.44 for staff service quality and 3.16 for convenience. This makes it to be the least of the three destination components. 


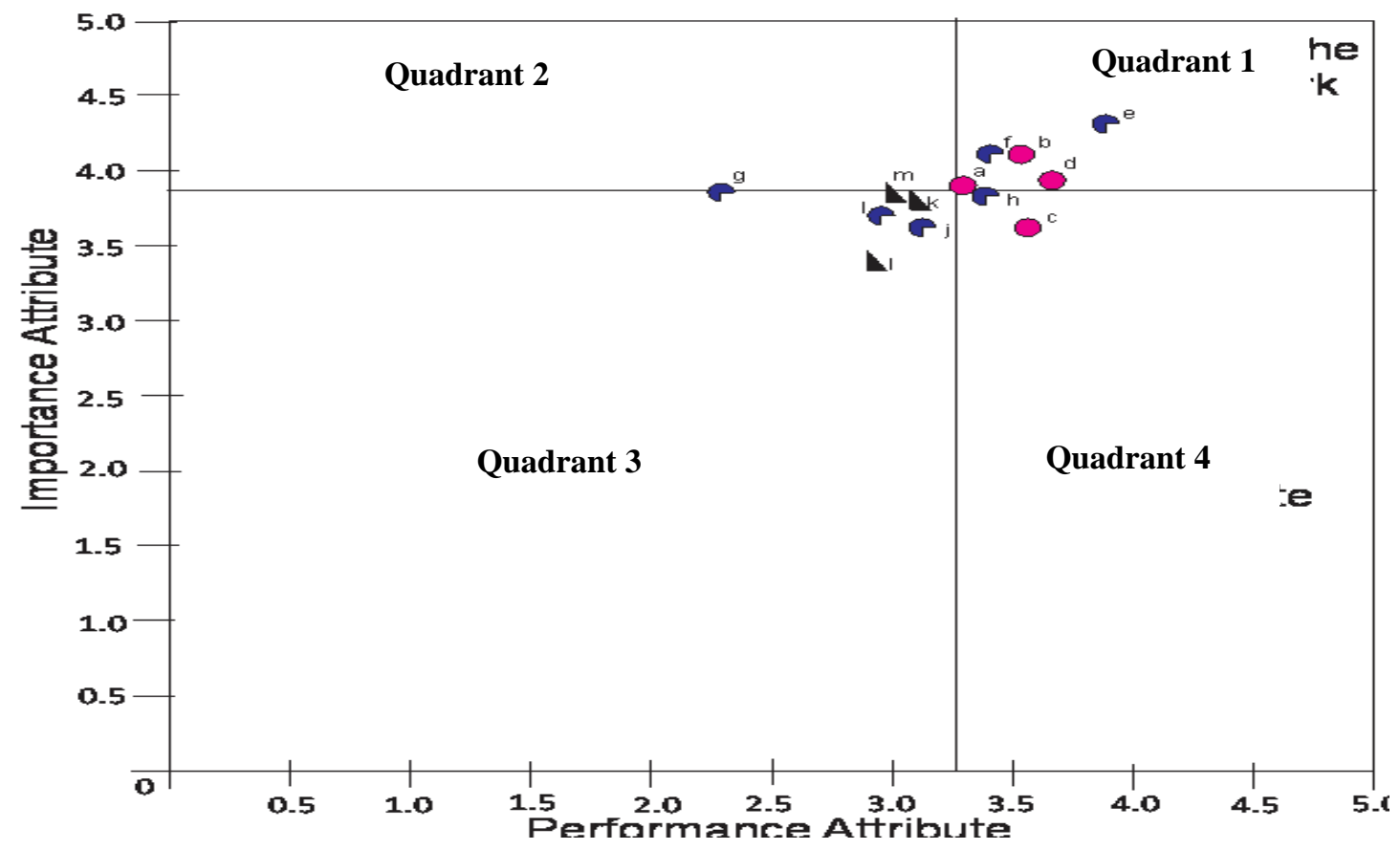

Source: Field survey, 2018

Figure 2: Destination Attributes on IPA Grid

Next, attributes of destination components were plotted in an Importance - Performance matrix/grid. The results obtained as shown in Figure $\mathbf{2}$ places environment, image, style, (accommodation) staff service quality and room quality in quadrant 1 suggesting that high importance and high impression ("Keep the good work"). As destination attractiveness attributes, these can be viewed as the opportunities of the destination appeal for the tourist market in Zaria. It suggests the key areas on which destination marketing can be further developed. What is interesting is the representation of three out of four attraction attributes fell in this quadrant.

Similarly, the presence staff service quality and room quality (accommodation attributes) in this quadrant projects are another core appeal of the destination, which can be further packaged effectively in the destination positioning exercises.

Destination component attributes falling in quadrant 2, high importance and low impression ("Concentrate here") are business service and (transport) Staff service quality, therefore these are destination attribute areas seen as threats, where destination development and marketing efforts need more attention to turn them into areas of perceived strengths for the destination. Comparing the relative positions of the attractions in this quadrant, reveal that business service attributes being placed higher in the quadrant offers more potential in improving the destination attractiveness for Zaria. Therefore, business service attributes, one of the important attractions for the destination, needs more attention in development and marketing for enhancing the quality of business and conference tourism and its appeal. Attributes which fall in the quadrant 3 low importance and low impression ("Low Priority") are Value and food quality, General amenities, System quality and Convenience. At an aggregate level of assessment, these destination component attributes appear less significant for enhancing the destination appeal for tourists compared to other attributes in quadrant 1 and quadrant 2 . This finding, especially with regard to accommodation's Value and food quality, appears contradictory to some of the insights obtained during the initial stage of study using interviews with tourists and managers where the importance of Value and food quality were repeatedly highlighted by the respondents was rate high.

Lastly, Destination attributes spotted in the quadrant 4 low importance, high impression ("Possible overkill") are fun and security. This is strength to the location, indicating that at an aggregate level of assessment as destination attraction elements, they are perceived better than what is expected. Nevertheless, the possibility of unique segments of tourists who seek high levels of quality from fun experience and accommodation's security may demand the importance of taking initiatives to improve quality in these attributes. 
Table 2: Location of the Destination Attributes/Sub-Components

\begin{tabular}{lll}
\hline Components & No of Sub-Components & Position in Quadrant
\end{tabular}

\begin{tabular}{lll}
\hline Attraction & 4 & 3 in Qudr. 1; 1 in Qudr. 4 \\
Accommodation & 6 & 2 in Qudr. 1; 1 in Qudr. 2 \\
& & 2 in Qudr. 3; 1 in Qudr. 4 \\
Accessibility & 3 & 1 in Qudr. 2; 2 in Qudr. 3
\end{tabular}

Source: Field survey, 2018

From the IPA grid Figure 2, and Table: $\mathbf{2}$ it is evident that attraction with three of its sub-components in quadrant 1 and one subcomponent in quadrant 4 prove to be the most attractive component in the study area followed by accommodation with accessibility having a sub-component in quadrant 2 and two sub-components in quadrant 3 as the least of the three components. With this attraction prove to be the primary destination component i.e. main attractant, while accommodation and accessibility as secondary attractants (Facilitators) in the destination.

Table 3: Tourist Numerous Visitations

\begin{tabular}{llc}
\hline No of Attractions visited & Types of attractions visited/Count & Total \\
\hline $\mathbf{1}$ & Educational (34), Medical (20), Business and conf. (2) & $\mathbf{5 6}$ \\
& & $23.83 \%$ \\
$\mathbf{2}$ & Rel. \& educational (56), Mon./crafts \& ecotourism (14), Cultural \& ecotourism & $\mathbf{1 3 9}$ \\
& (27), Educational \& Cultural (19), Cultural \& Medical (10), Ecotourism \& & $59.15 \%$ \\
$\mathbf{3}$ & educational (4), Medical \& ecotourism (9), & $\mathbf{4 0}$ \\
& Ecotourism, Cultural \& educational (15), Bus. \& Conf., ecotourism & $17.45 \%$ \\
\hline
\end{tabular}

Source: Field survey, 2018

The findings indicates that, many people came visiting friends and family and having in mind to pay visit to one attraction in particular as seen in the Table. 3, eventually out of tourists attracted to Zaria, 59.15\% end-up visiting two different attractions, $23.83 \%$ only one type and $17.45 \%$ to three different types during their short stay at the destination. 
Table 4: Ranking of Attraction Elements According to Purpose of Visit

\begin{tabular}{|c|c|c|c|c|c|c|c|c|c|}
\hline & $\begin{array}{c}\text { Education } \\
\text { al }\end{array}$ & Medical & Cultural & Mon. \& Crafts & Religious & Eco. & Buss. \& Conf. & Sport & Total \\
\hline Frequency & 71 & 41 & 32 & 30 & 23 & 21 & 12 & 5 & 235 \\
\hline Rel. freq & .30 & .17 & .14 & .13 & .10 & .09 & .05 & .02 & 1.00 \\
\hline Rank & $1^{\text {st }}$ & $2^{\text {nd }}$ & $3^{\text {rd }}$ & $4^{\text {th }}$ & $5^{\text {th }}$ & $6^{\text {th }}$ & $7^{\text {th }}$ & $8^{\text {th }}$ & \\
\hline
\end{tabular}

Source: Field survey, 2018

The second level of analysis carried out involved the ranking of attraction elements. In the first level of analysis, attraction was established to be the most significant in the destination. Therefore, it is important to query the attractiveness of attraction's elements in the destination.

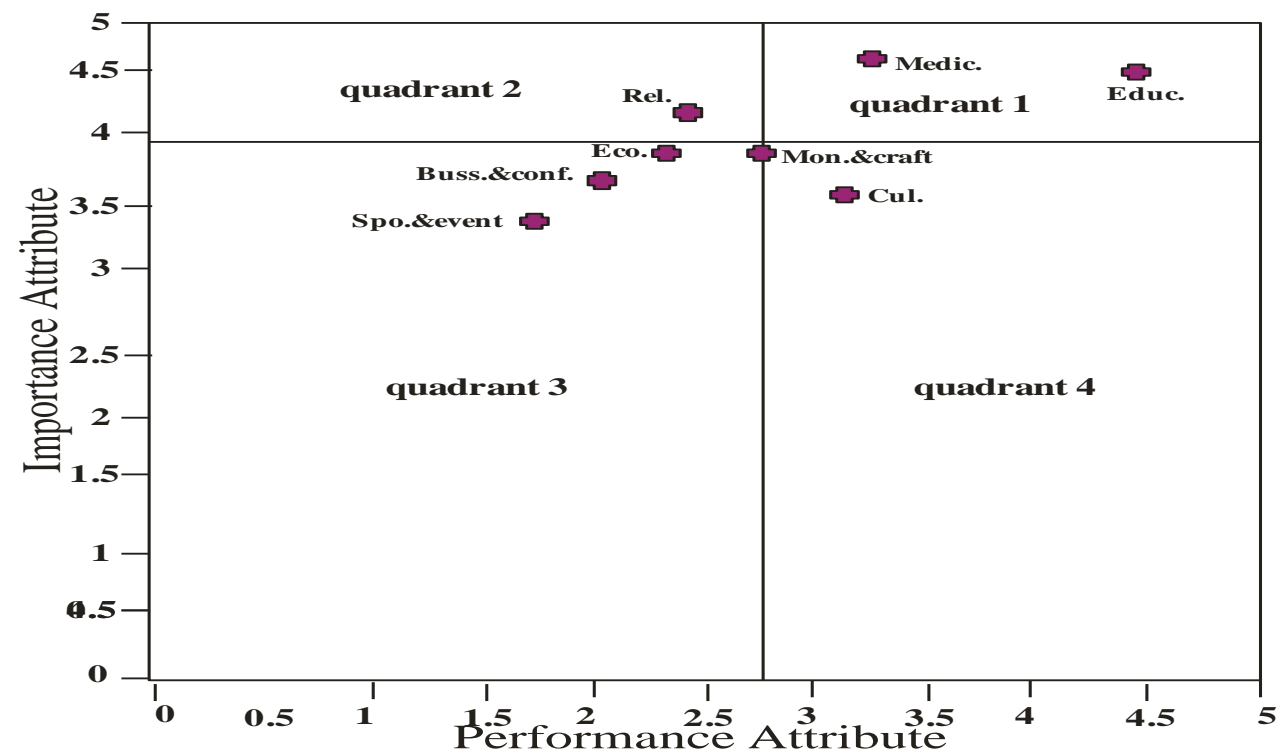

Fig 3: Attraction Elements on IPA grid

Further analysis was conducted in which the co-ordinates of the elements were plotted on the IPA grid, Fig: 3. this established educational and medical tourism to fall in quadrant 1 (keep up the good work) revealing it to be the strength of attraction in the destination.

Religious element is the only element that fell in quadrant 2 (concentrate here) indicating that if attention is paid to it, it can be a major attraction and thus boost the destination attractiveness. Monuments \& crafts tourism, eco-tourism, business and conference and sport and events tourism fell in quadrant 3 (low priority) suggesting that these elements should have the least investment of the planner or developer for it will yield little or no positive result. But in this quadrant monuments. $\&$ crafts tourism seems to have a prospect of being attractive in the destination due to its location on the grid. Finally, the only element spotted in quadrant 4 is cultural tourism. This quadrant indicate that to improve this element the level of effort or resources on the element should be maintain to more attractive at the destination. The purposes of visiting educational attractions stand-out to be the most attractive element in Zaria, with $30.21 \%$. This can be traced to Zaria having over 7 tertiary, training and research institutions, also hosting $\mathrm{ABU}$, the oldest university in the region and NCAT, the only Aviation College in West Africa. $2^{\text {nd }}$ on the ranking is medical/health element with $17.45 \%$, this can be drawn from the destination accommodating a standard and well equipped teaching hospital 
(ABUTH) in the region and two nursing colleges (ABUTH; St. Luke's, Wusasa).

Cultural (13.62\%), monument \& Craft $(12.77 \%)$ were the $3^{\text {rd }}$ and $4^{\text {th }}$ respectively on the ranking list, this can be connected to the destination being an ancient town, historic kingdom and traditional emirate that hold tightly to its arts and cultural values such as dying, murals, leather work etc. Religious element has 9.79\% and was rated $5^{\text {th }}$. Apart from the elements listed above Zaria had also been the centre for Islamic study and "fudiyyah" for centuries. Thus, many Islamic clerics can be linked to studying in Zaria such as Malam Isa Madaka, Malam Ibrahim Kakaki, Ibrahim Yaqoub El Zakzaky. It has also nurtured some religious movement which has contributed to its attractiveness such as the Islamic Movement in Nigeria which came as an independent body since early 1980s. Also annual Maulud celebration by the members of this Islamic movement attracts thousands to Zaria.

Ecotourism with $8.94 \%$ was $6^{\text {th }}$ in ranking, this can be associated to some amazing landform and scenic water bodies present at the destination such as Kufena Rock, ABU dam. Business \& conferencing $(5.11 \%)$ and sport elements were $7^{\text {th }}$ and $8^{\text {th }}$ respectively ranked on the list.

\section{CONCLUSION}

The local tourism board needs to be rejuvenated to enhance the local tourism industries. This is essential because for tourism to be more fascinating in Zaria the board had to champion the industry by implementing good policies towards drawing tourists likewise investors to the destination, amongs others. Zaria has all that it takes to imprint itself on the world tourism map, if the proposed recommendation can be effected in the destination to boost the attractiveness. Its attractions were averagely rated satisfactory, but it has to be upgraded for it is to meet up to an international standard to attract international tourists. Its accessibility performed poor, and this can hamper tourism industry if not amend in time.

This work did an x-ray on tourism industry in Zaria; the IPA technique can be conveniently applied to any destination for a thorough analysis. Also, each of the components can be assessed deeply using this same technique for further knowledge and exploration in the industry.

\section{REFERENCES}

Barsky, J.D. (1995). World-Class Customer Satisfaction. Chicago, USA. Irwin Publishing.

Chon, K. (1990). The Role of Destination Image in Tourism: A review and discussion. The Tourist Review,
Chukwuemeka I. (2009). Nigeria: Successes And Challenges, Tourism Review.com DESTINATION: Nigeria-Unspoiled and authentic.. http://www.renewreservation.com

Echtner, C.M. And Ritchie, J.R.B. (2003). The Meaning and Measurement of Destination Image. The Journal of Tourism Studies Vol. 14, No. 1, MAY '03 37

Edward, M. and George, B.P. (2008) Destination Attractiveness of Kerala as an International Tourist Destination: An Importance-Performance Analysis, a presentation in Conference on Tourism in India - Challenges Ahead, 15-17 May 2008,

Evans, M.R. and Chon, K. (1989). Formulating and Evaluating Tourism Policy Using Importance-Performance Analysis. Hospitality Education and Research Journal, 13(3):1-14.

Ford, J.B., Joseph, M. and Joseph, B. (1999). ImportancePerformance Analysis as a Strategic Tool for Service Marketers: the case of service quality perceptions of business students in New Zealand and the USA, The Journal of Services Marketing,4(2):11-27.

Go, F., and Zhang, W. (1997). Applying ImportancePerformance Analysis to Beijing as an International Meeting Destination. Journal of Travel Research Spring, 3(2):20-33.

Iatu, C., and Bulai, M. (2011) New Approach in Evaluating Tourism Attractiveness in the Region of Moldavia (Romania). The Journal of Tourism Studies Issue 2, Volume 5, 2011.

Kotler, P., Bowen, J., and Makens, J. (2005). Marketing for Hospitality and Tourism. NY: Pearson Education.

Lovelock, C., Patterson, P.G., and Walker, R. H. (1998). Services Marketing. Sydney: Prentice Hall.

Moscardo, G. (2001). Visitor Evaluations of Built Tourist Facilities: Pontoons on Great Barrier Reef. The Journal of Tourism Studies Vol. 12, No. 1, May 2001.

Muazu, M. (2010). Glimpses of Kaduna State. Utivision Ltd., Kaduna, Nigeria.

Mullins, G.W. and Spetich, B. L. Schultz (1987). ImportancePerformance Analysis, Vol. 11 Number 3. School of Natural Resources Ohio State University, USA.

O’Neill, M.A., Palmer, A., and Charters, S. (2002). Wine Production as Service Experience: Effects of Service Quality on Wine Sales. Journal of Services Marketing, 16 (4)..

Pearce, P.L. (1991). Analyzing Tourist Attractions. The Journal of Tourism Studies Vol. 2, No. $1 \quad$ May 1991. 
The Cities Alliance, (2007). Understanding Your Local Economy (A Resource Guide for Cities), 1818 H Street, NW Washington, D.C. 20433, U.S.A. http://www.citiesalliance.org www.wikipeadia/USA/tourist_trap Retrieved on 1st July, 2014. use, distribution, and reproduction in any medium, provided the original work is cited appropriately. 